九州大学学術情報リポジトリ

Kyushu University Institutional Repository

\title{
Erosion sensor using time-resolved cavity ring- down spectroscopy for Hall thrusters
}

Egawa, Yusuke

Department of Advanced Energy Engineering Science, Kyushu University

Yamamoto, Naoji

Faculty of Engineering Science, Kyushu University

Yamaguchi, Atsushi

Department of Advanced Energy Engineering Science, Kyushu University

Morita, Taichi

Faculty of Engineering Science, Kyushu University

http://hdl. hand le. net/2324/4103905

出版情報: Review of scientific instruments. 91 (113105)，pp.1-8，2020-11-06 バージョン：

権利関係 : 


\title{
Erosion sensor using time-resolved cavity ring-down spectroscopy for Hall thrusters
}

\author{
Yusuke Egawa, ${ }^{1, a)}$ Naoji Yamamoto, ${ }^{2}$ Atsushi Yamaguchi, ${ }^{1}$ and Taichi Morita ${ }^{2}$ \\ ${ }^{1}$ Department of Advanced Energy Engineering Science, Kyushu University Kasuga, Fukuoka \\ 8168580, Japan \\ ${ }^{2}$ Faculty of Engineering Science, Kyushu University Kasuga, Fukuoka 8168580, Japan \\ a) Author to whom correspondence should be addressed: yusuke@aees.kyushu-u.ac.jp
}

\begin{abstract}
A high-sensitivity sensor to measure titanium atom density based on time-resolved cavity ring-down spectroscopy (CRDS) was developed to monitor the wall erosion and predict the lifetime of Hall thrusters. The minimum detection limit for the sensor was dependent on the discharge current oscillation in the Hall thruster. A Volterra engine management system was employed for time-resolved measurements to develop the time-resolved CRDS system, which was synchronized to the discharge current oscillation. The results confirmed that the path-integrated number density of sputtered titanium atoms was synchronized with the discharge current oscillation. The minimum detection limit was decreased by approximately $30 \%$ from $2 \times 10^{12}$ to $6 \times 10^{11} \mathrm{~m}^{-2}$.
\end{abstract}

\section{INTRODUCTION}

All-electric propulsion satellites have attracted considerable attention since Boeing successfully achieved the orbital transfer and attitude control of a satellite using ion thrusters in 2015. ${ }^{1}$ In such satellites, orbital rising and north/south station keeping of the spacecraft are accomplished using electric propulsion rather than conventional methods based on chemical propulsion. The primary advantage of all-electric propulsion satellites is a reduced propellant mass compared with chemical propulsion. ${ }^{2}$ For example, SpaceX launched the first 60 satellites of its Starlink constellation in 2019. A key benefit of all-electric propulsion is that it allows launching the same number of satellites with fewer launches. ${ }^{3}$ For Boeing, two all-electric propulsion satellites could be launched simultaneously, though one satellite was mounted on one rocket. In 2017, two years after the demonstration of Boeing's all-electric satellites, Europe's all-electric telecom satellite, Eutelsat 172B, was built for Eutelsat by Airbus and featured Hall thrusters rather than ion thrusters as the main propulsion system, which reached geostationary orbit above the Pacific Ocean. ${ }^{4}$ This journey only took 4 months to transfer from the initial to the desired orbit, instead of the normal 6 months. Given that shorter delivery times are of great importance to satellite users, it is expected that Hall thrusters will be increasingly adopted for all-electric propulsion satellites.

A Hall thruster contains an acceleration channel to which a radial magnetic and an axial electric 
field are applied. The magnetic field is applied using the inner and outer coils, while the electric field is applied using a potential difference between the anode and outer cathode. Electrons are emitted from the cathode and used for both ionization and neutralization. The electrons from the cathode are trapped by the magnetic field, and a Hall current is induced along the azimuthal direction due to the $\mathrm{E} \times \mathrm{B}$ drift. The high-energy electrons collide with and ionize the neutral particles of the propellant, which generates ions and electrons. The produced ions are accelerated in the acceleration channel by the electric field to generate thrust as the reaction force. The electrons emitted from the cathode and those produced by ionization then progress towards the anode due to the electric field.

In a Hall thruster, electrons exist in the acceleration channel without any space-charge limitations. Thus, a high thrust density can be achieved, which allows Hall thrusters to be more compact than ion thrusters. In addition, the thrust-to-power ratio of Hall thrusters exceeds that of ion thrusters. ${ }^{5}$ Therefore, the thrust is greater for Hall thrusters under the same operating conditions, as a constant electric power is generated by the solar cell. Such a process effectively shortens the transition period to reach the desired orbit. The 702SP launched by Boeing used an ion thruster (the XIPS-25) with a thrust-to-power ratio of $37 \mathrm{mN} / \mathrm{kW}$ and required approximately 6 months to reach the target orbit. The Eutelsat 172B launched by Airbus used Hall thrusters (the PPS-5000) with a thrust-to-power ratio of $64 \mathrm{mN} / \mathrm{kW}$ and took approximately 4 months to attain the target orbit. In addition to the approximately 4000 hours of operation required for orbital rising, more than 3000 hours of operation were required for north/south station keeping.

The primary factor that limits the lifetime of Hall thrusters is wall erosion due to ion sputtering. ${ }^{6}$ Therefore, measuring sputter erosion is essential to evaluate thruster lifetimes. However, conventional long-term wear tests are extremely costly in terms of both human resources and time. ${ }^{7}$ Moreover, there are numerous experimental parameters to consider, and the erosion of the Hall thruster wall is relatively slow, which makes conventional measurement approaches impractical. Therefore, in situ and high sensitivity measurement systems for sputter erosion are required. Lee et al. demonstrated the effectiveness of sputter measurement systems based on cavity ring-down spectroscopy (CRDS) for erosion measurements in electric propulsion systems. ${ }^{8,9} \mathrm{CRDS}$ is a type of laser absorption spectroscopy that permits quantitative in situ measurements. ${ }^{10-13}$

In CRDS, an optical cavity composed of two high-reflection mirrors confines the incident laser beam. This beam is reflected multiple times using mirrors, and if the mirror reflectivity is $99.95 \%$, the length of the probe optical path is expanded up to 2000 times, leading to extremely sensitive measurements. When the absorbing species has the same excitation wavelength as the emission wavelength of the laser in the cavity, the species absorbs the laser energy. The transmitted light is called the "ring-down signal," where the ring-down time is defined as how long it takes the signal to decrease below a factor of 1/e. The ring-down time is calculated using the attenuation time of the transmitted light by fitting an exponential decay curve, as illustrated by the black line in Fig. 1. The 
absorbance and density of the sputtered atoms can be calculated using the ring-down time. Therefore, CRDS is a promising method to perform in situ erosion measurements in Hall thrusters.

The use of CRDS to perform such measurements requires overcoming several challenges. Fluctuations in the absorbance due to changes in the density of the sputtered particles are one limitation that affects the detection limit. Discharge current oscillations are caused by fluctuations in the plasma density. The ion flux that collides with the wall surface is transient, which causes a variable amount of wear. A previous study showed that the ion current that flows into the wall is synchronized with the discharge current oscillations. Therefore, the absorbance histogram has two peaks with a relatively high minimum detection limit. ${ }^{14}$ These observations were ascribed to oscillations in erosion in association with the discharge current oscillation of the Hall thruster at approximately $20 \mathrm{kHz}$. If the histogram does not have a Gaussian distribution, the measurement uncertainty is derived from random errors and other potential causes, such as fluctuations in the density of sputtered atoms. Thus, a conventional time-averaged CRDS system has a large measurement uncertainty. To reduce this uncertainty, CRDS measurements should be performed during each phase of the discharge current oscillations. Therefore, it is essential to synchronize the erosion measurement system with discharge current oscillations using a time-resolved system.

In time-averaged CRDS measurements, the ring-down time is averaged in the bin of a given laser frequency. In time-resolved CRDS measurements, the ring-down time is averaged in the bin of a given laser frequency and a given normalized time. Therefore, the bins of the time-resolved CRDS measurements are finer than time-averaged results. The adoption of a time-resolved CRDS improves the sensitivity of time-variant concentration measurements and contributes to revealing the physics behind erosion in Hall thrusters. However, time-resolved CRDS requires a complex measurement system to lock the time-variant concentration and requires more data sets compared with conventional time-averaged CRDS. In this study, the same data sets were used for the time-resolved and time-averaged methods and were analyzed with a $200 \mathrm{~W}$ Hall thruster developed at Kyushu University to verify the effects of time-resolved CRDS. The time-resolved CRDS was based on measurements that use the phase of a discharge current oscillation. 


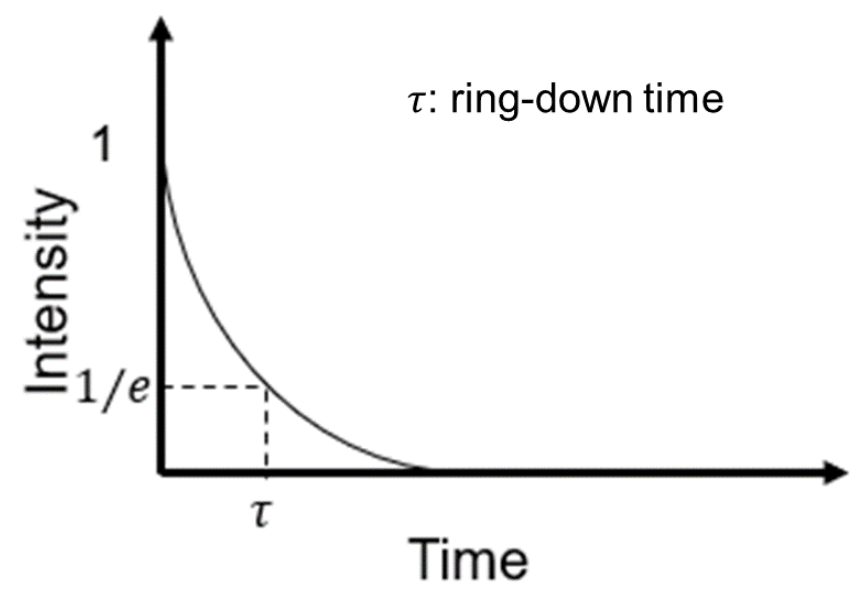

FIG. 1. Definition of ring-down time.

\section{EXPERIMENTAL METHODS}

\section{A. CRDS system}

A schematic diagram of the CRDS system is presented in Fig. 2. A Littrow external cavity diode laser (DL100 pro, Toptica) was used to measure the transition line of titanium at $394.86708 \mathrm{~nm}$ in air ${ }^{15}$ by scanning the wavelength range from 394.86424 to $394.87224 \mathrm{~nm}$. The mode-hop-free scanning range was approximately $20 \mathrm{GHz}$ with a laser linewidth below $10 \mathrm{MHz}$, corresponding to $5.2 \times 10^{-6} \mathrm{~nm}$

The probe laser was divided into probe and reference light using beam splitters. The probe light was chopped using a trigger when the ring-down signal exceeded a pre-defined threshold and was modulated to the first-order diffracted light using an acousto-optic modulator (AOM). The laser intensity was reduced using a neutral density (ND) filter to avoid absorption saturation. The peak laser power coupled into the cavity was $1.8 \mu \mathrm{W}$; therefore, the peak power in the cavity corresponding to the peak ring-down signal was estimated at $3.6 \mathrm{~mW}^{16}$ with a mirror reflectivity of $99.95 \%$. The laser passed the cavity $30 \mathrm{~mm}$ downstream of the Hall thruster. The cavity length was $0.55 \mathrm{~m}$, and the signal was detected using a photomultiplier tube (PMT). The reference light was used for optogalvanic spectroscopy to obtain the relative frequency of the laser with respect to the absorption frequency of ${ }^{48} \mathrm{Ti}$. The light was chopped using an optical chopper and passed through a hollow-cathode lamp (HCL) with a titanium electrode. The titanium spectrum contains numerous peaks due to its hyperfine structure. ${ }^{17}$ The spectra were separated as ${ }^{46} \mathrm{Ti},{ }^{47} \mathrm{Ti},{ }^{48} \mathrm{Ti},{ }^{49} \mathrm{Ti}$, and ${ }^{50} \mathrm{Ti}$ based on isotope shifts. Among them, the spectra for ${ }^{47} \mathrm{Ti}$ and ${ }^{49} \mathrm{Ti}$ included fine peaks due to nuclear spin interactions, which caused a splitting of the energy levels. ${ }^{18}$ In this study, the optogalvanic signals were fit using the isotope shifts for ${ }^{46} \mathrm{Ti},{ }^{48} \mathrm{Ti}$, and ${ }^{50} \mathrm{Ti}$ based on three Gaussian functions.

An etalon (free spectral range $=1.5 \mathrm{GHz}$ ) was used as the frequency reference. A titanium 
target was set $30 \mathrm{~mm}$ downstream of the laser path. The head of an M6 (10 mm) hexagonal bolt was used as the target. During operation of the Hall thruster, the ions were exhausted before colliding with the titanium target, which caused sputtering of titanium atoms that could be detected in the absorption signal. As a result, the high-reflection mirrors were contaminated with sputtered particles from the Ti target and the wall of the vacuum chamber, which reduced the mirror reflectivity. Therefore, a gas purge system as created using a 3D printer was installed. This system dispensed a uniform flow of Ar gas fromr four directions to each of the mirrors. In addition, the thruster and high-reflection mirrors were installed in a carbon cylindrical box. The mirrors and thruster were then separated with a carbon wall, and an iris was used for the laser path.

A typical ring-down signal and profiles for the discharge voltage and current are presented in Fig. 3. The ring-down time was calculated from the attenuation of the transmitted light, as illustrated by the black line. There are two sparks around 40 and $90 \mu$ s in Fig. 3, which are noise that comes from the Volterra engine when locking the discharge current oscillation at $20 \mathrm{kHz}$. The $\mathrm{T}$ is the cycle time of the discharge current oscillation, which was measured as $50 \mu \mathrm{s}$, and $\mathrm{t}$ is defined as the time between the minimum peak of the discharge current and the reference point of the ring-down signal. The reference point was observed $2.2 \mu$ s after the ring-down signal exceeded $1.4 \mathrm{~V}$, which was set as the threshold because the AOM shutter closed completely within $2.2 \mu \mathrm{s}$. When the ring-down signal was attenuated, the decrease from the reference point was fit using an exponential function to calculate the ring-down time and absorbance.

In this work, the discharge current oscillation was locked at $20 \mathrm{kHz}$ using a Volterra engine management system to synchronize the time-resolved measurement with the discharge current oscillation. The Volterra engine is a harmonized power processing unit that can lock the discharge current oscillation at a constant frequency. ${ }^{18,19}$ The time of the obtained ring-down signal was then aligned with the normalized time of the oscillation. Thus, the ionization instability in the Hall thruster could be controlled, and the discharge current oscillation could be locked at the applied frequency. The time resolution was set to one-tenth of the oscillation cycle at $5 \mu \mathrm{s}$, with a frequency resolution of $1 \mathrm{GHz}$ (wavelength resolution of $0.52 \mathrm{pm}$ ).

The phase of the discharge current oscillation dictates the normalized time, which is defined as:

$$
\text { Normalized time }=\frac{t}{T}
$$

The data for fitting were obtained $2.2 \mu$ s after the ring-down signal exceeded the threshold due to delay in the devices. The ring-down times were collected with a relative frequency and normalized time for the time-resolved measurements. In the time-averaged CRDS measurements, the ring-down time was averaged in a given laser frequency bin. In the time-resolved CRDS measurements, the ring-down time was averaged over a given laser frequency bin and a given normalized time. Thus, the bin for the time-resolved CRDS measurements was finer than that of the time-averaged results. 
To verify the effect of the time-resolved CRDS, the same data sets were analyzed using both time-resolved and time-averaged methods.

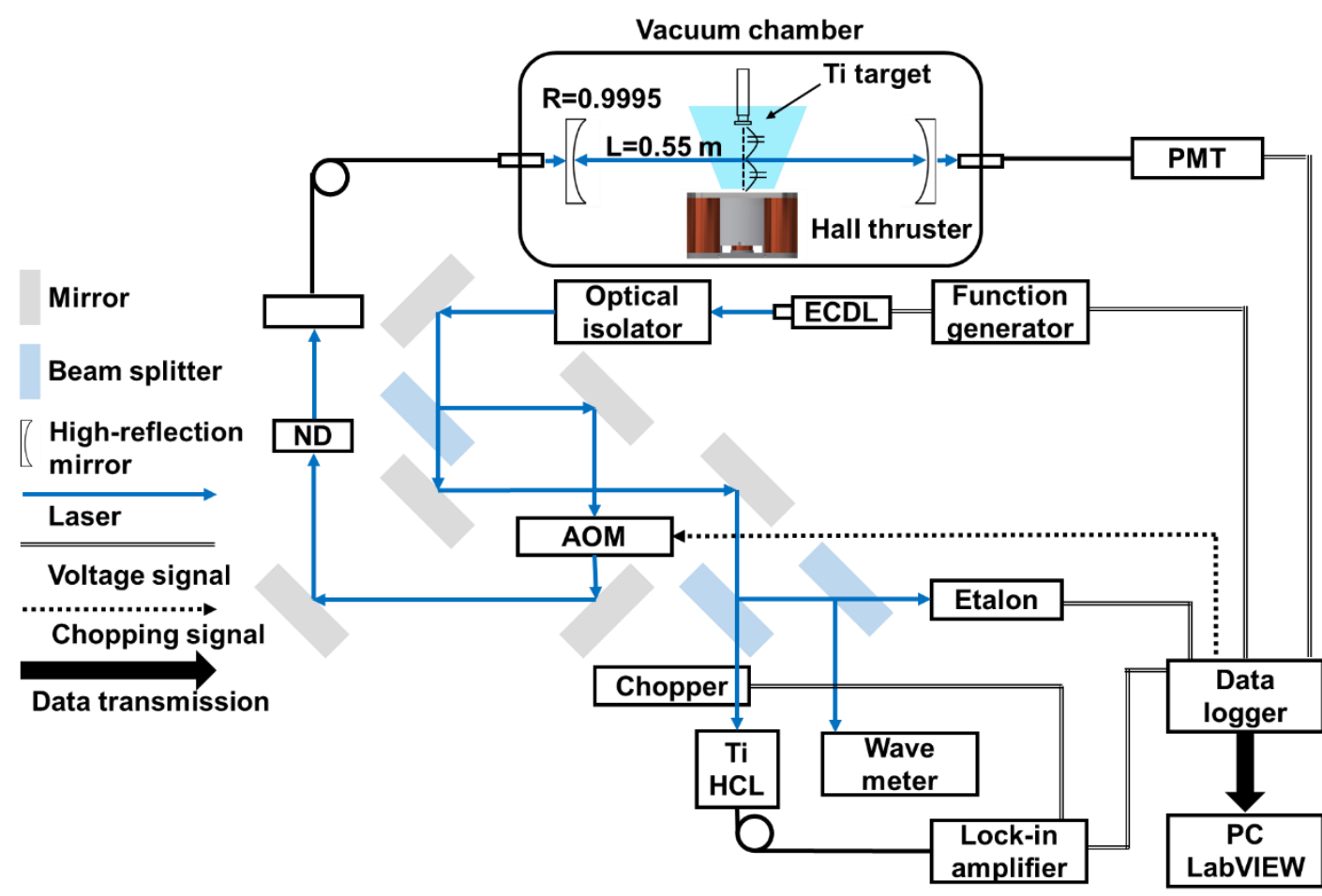

FIG. 2. Schematic of the developed CRDS system. The distance between the Hall thruster and the target is $60 \mathrm{~mm}$, and the laser path is perpendicular to the thruster axis and passes through the midpoint of the target and the thruster. The titanium target comprises head of an M6 (10 mm) hexagonal bolt. 


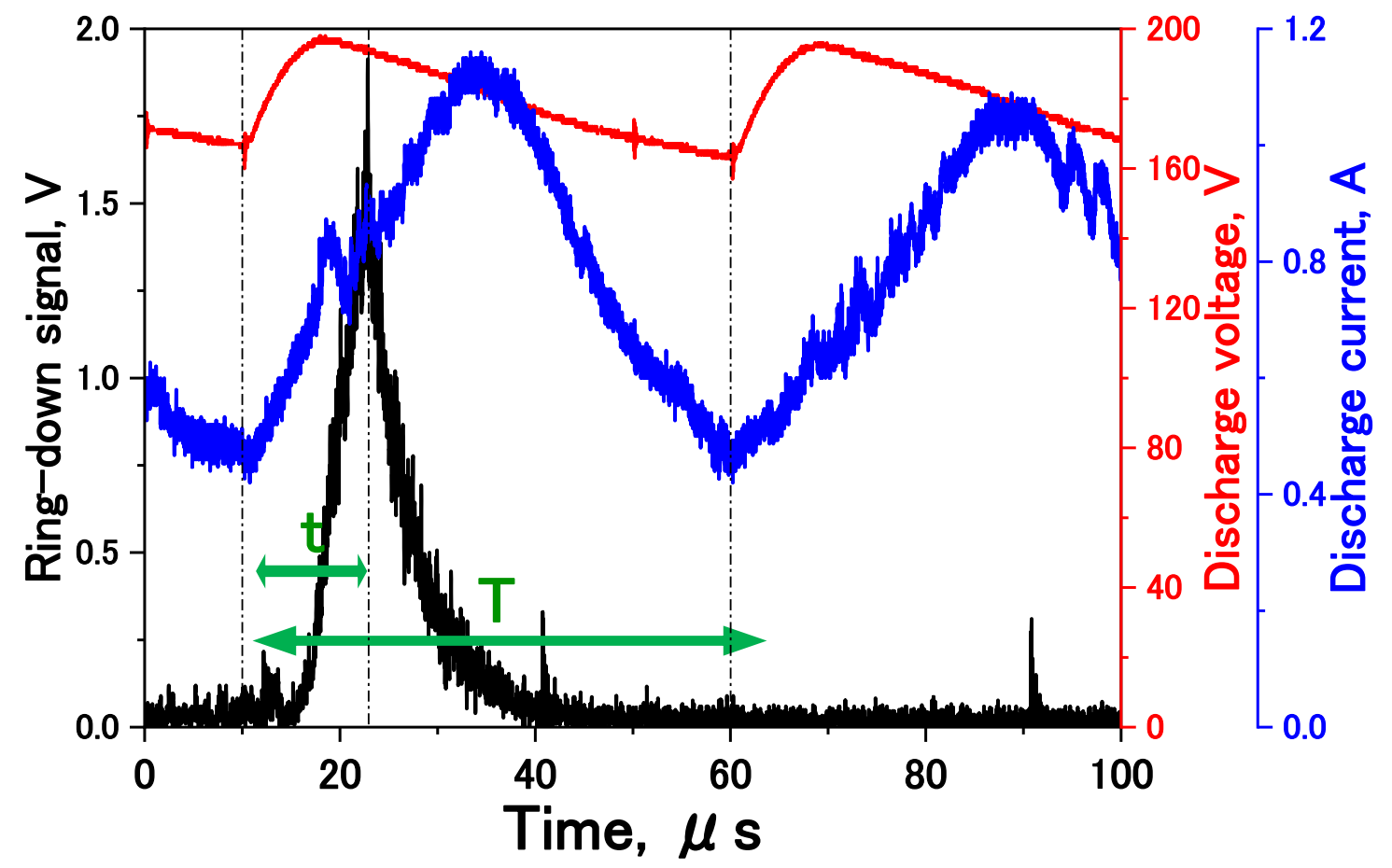

FIG. 3. Time variations in the ring-down signal (black), discharge current (blue), and discharge voltage (red).

\section{B. Hall thruster}

This study used a $200 \mathrm{~W}$ magnetic-layer-type Hall thruster as the ion source and a hollow cathode (Veeco, HC252) as the electron source. The inner and outer diameters of the acceleration channel in the Hall thruster were 34 and $59 \mathrm{~mm}$, respectively, as shown in Fig. 4. The size of the thruster was $120 \mathrm{~mm} \times 120 \mathrm{~mm} \times 72 \mathrm{~mm}$. The wall was composed of Shapal Hi-M Soft, which is a sintered composite ceramic based on aluminum nitride ( $\mathrm{AlN}$ ) and boron nitride (BN). As this study aims to validate the time-resolved CRDS system, titanium was not included in the wall in the Hall thruster. The anode was installed $25 \mathrm{~mm}$ upstream of the thruster exit. The magnetic circuit was similar to that of a conventional Hall thruster, which contained two types of solenoid coils to create and adjust the radial magnetic field in the acceleration channel. Four outer coils were positioned at each corner outside of the channel, and an inner coil was installed at the center of the thruster.

The propellant was xenon gas, and the flow rate was controlled using mass flow controllers. The mass flow rates at the anode and cathode were 0.68 and $0.27 \mathrm{mg} / \mathrm{s}$, respectively. To reduce the 
influence of heat on the mirrors, the Hall thruster was mounted inside an isotropic graphite box. During a given experiment, $0.15 \mathrm{mg} / \mathrm{s}$ of argon flowed in front of the high-reflection mirrors to avoid contamination by sputtered particles from the target and vacuum chamber walls.

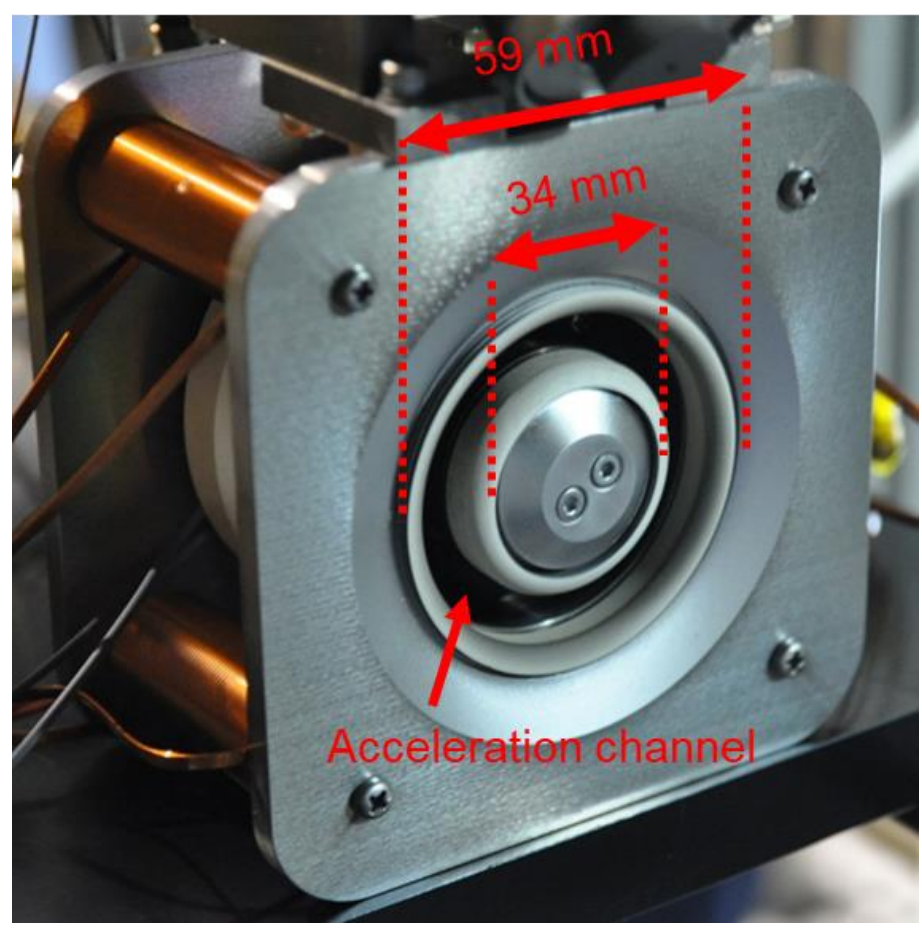

FIG. 4. Exterior of a Hall thruster.

\section{Vacuum facility}

The measurements were conducted inside a cylindrical vacuum chamber with a diameter of 1.0 $\mathrm{m}$ and length of $1.2 \mathrm{~m}$. The chamber was made of titanium-free SUS304 stainless steel; therefore, it did not affect the CRDS titanium measurements. The chamber was attached to a rotary pump, two turbomolecular pumps, and a cryogenic pump to provide an ultimate pressure below $7.0 \times 10^{-4} \mathrm{~Pa}$ and an operating pressure of $1.0 \times 10^{-2} \mathrm{~Pa}$.

\section{RESULTS AND DISCUSSION}

\section{A. Absorbance}

The time-averaged CRDS spectrum was calculated using the ring-down time, as shown in Fig. 5. The sample absorbance along the optical axis, $\operatorname{ABS}(v)$, was calculated as: ${ }^{16}$

$$
A B S(v) \equiv \int_{0}^{L} k(x, v) d x=\frac{L}{c}\left[\frac{1}{\tau(v)}-\frac{1}{\tau_{0}(v)}\right],
$$

where $k(x, v)$ is the absorption coefficient of the target atoms, $x$ is the position along the optical 
axis, $L$ is the optical length, $c$ is the speed of light, $\tau(v)$ is the ring-down time when sputtered titanium atoms exist in the cavity, and $\tau_{0}(v)$ is the ring-down time when the optical cavity is empty. The transmitted light is called the "ring-down signal," and the ring-down time is the time at which the transmitted light is reduced to $1 / \mathrm{e}$ times its initial value. The absorbance and density of the sputtered atoms was calculated using the ring-down time with absorbers, $\tau(v)$, and without absorbers, $\tau_{0}(v)$, which can be expressed as follows:

$$
\begin{gathered}
\tau(v)=\frac{L}{c\left[(1-R)+\int_{0}^{L} k(x, v) d x\right]} \\
\tau_{0}(v)=\frac{L}{c(1-R)^{\prime}}
\end{gathered}
$$

where $R$ is the mirror reflectance.

If the absorbance is balanced by the absorption and induced emission, as in Ref. 20, the total absorbance can be expressed as:

$$
k(v) d v=\frac{\mathrm{h} v}{c}\left(B_{i k} d N_{i}-B_{k i} d N_{k}\right)
$$

where, $i$ and $k$ indicate the $i$ and $k$ states, respectively; $\mathrm{h}$ is Planck's constant, $v$ is the transition frequency; $N_{i}$ and $N_{k}$ are the population densities of the $i$ and $k$ states, respectively; $B_{i k}$ and $B_{k i}$ are the Einstein $\mathrm{B}$ coefficients from $i$ to $k$ and $k$ to $i$; and $d N_{i}$ is the population densities of the $i$ state with a correspondence to $d v$. The relationship between the Einstein coefficients A and B is expressed as follows:

$$
A_{k i}=\frac{8 \pi h v^{3}}{c^{3}} \frac{g_{i}}{g_{k}} B_{i k}=\frac{8 \pi h v^{3}}{c^{3}} B_{k i}
$$

where $g_{i}$ is the $i$ state degeneracy, and $g_{k}$ is the $k$ state degeneracy.

Integrating Eq. (2) over the frequency and using Eqs. (5) and (6) when assuming the population ratio for the $k$ state to $i$ state species is negligible provides the integrated absorption coefficient as:

$$
\begin{gathered}
\int_{-\infty}^{\infty} k(v) d v=\int_{-\infty}^{\infty} \frac{h v}{c}\left(B_{i k} d N_{i}-B_{k i} d N_{k}\right) d v=\frac{h v}{c}\left(B_{i k} N_{i}-B_{k i} N_{k}\right) \\
=\frac{c^{2}}{8 \pi v^{2}} \frac{g_{k}}{g_{i}} A_{k i} N_{i}\left(1-\frac{g_{i}}{g_{k}} \frac{\mathrm{N}}{N_{i}}\right) \\
=\frac{c^{2}}{8 \pi v^{2}} \frac{g_{k}}{g_{i}} A_{k i} N_{i} \cdot\left(\because \frac{g_{i}}{g_{k}} \frac{\mathrm{N}}{N_{i}} \ll 1\right) .
\end{gathered}
$$

Therefore,

$$
N_{i}=\frac{8 \pi v^{2}}{A_{k i} c^{2}} \frac{g_{i}}{g_{k}} \int_{-\infty}^{\infty} k(v) d v .
$$

Integrating this equation along the cavity axis gives the path-integrated number density of the ground 
state of titanium, $\int N_{i} d x$, as follows: $:^{20-22}$

$$
\int_{0}^{L} N_{i} d x=\frac{8 \pi v^{2}}{A_{k i} c^{2}} \frac{g_{i}}{g_{k}} \int_{-\infty}^{\infty} A B S(v) d v .
$$

Here, the population ratio of the excited to the ground state species is assumed to be negligible due to the small ratio of the excited electron temperature in the plume region to the energy difference between the ground and the excited states of the target resonance line at $3.14 \mathrm{eV}$. The transition parameters for the ground state of Ti atoms are presented in Table I. ${ }^{23}$

During measurements, the laser scan cannot cover the entire absorption line profile because the mode-hop-free range of the laser is approximately $20 \mathrm{GHz}$. Spectrum fitting was conducted using six Gaussian functions based on the three isotope shifts of ${ }^{46} \mathrm{Ti},{ }^{48} \mathrm{Ti}$, and ${ }^{50} \mathrm{Ti}$ and the Doppler shift of the absorption line. The isotope shifts for ${ }^{47} \mathrm{Ti}$ and ${ }^{49} \mathrm{Ti}$ are neglected because their effects on the spectrum are relatively small. In the CRDS measurement, the Doppler shows both blue- and red-shifts because the propagation direction of the probe laser beam changed due to the high-reflectance mirrors in the optical cavity. If the differential sputtering yield is symmetric with respect to the axis perpendicular to the probe laser beam, two different shifts occur both before and after the centerline. For simplicity, the spectrum fitting function assumes a Gaussian distribution such that the amplitude of the spectrum is proportional to the abundance ratio of the isotopes. ${ }^{24}$ The full-width-at-half-maximum (FWHM) and frequency shift of each Gaussian distribution are the same, and the peak frequency of the ${ }^{46} \mathrm{Ti}$ and ${ }^{50} \mathrm{Ti}$ are shifted by -1.75 and $1.63 \mathrm{GHz}$, respectively, relative to ${ }^{48} \mathrm{Ti}$ due to the isotope shifting in accordance with Ref. 16. The abundance ratios of ${ }^{46} \mathrm{Ti},{ }^{48} \mathrm{Ti}$, and ${ }^{50} \mathrm{Ti}$ are presented in Table II.

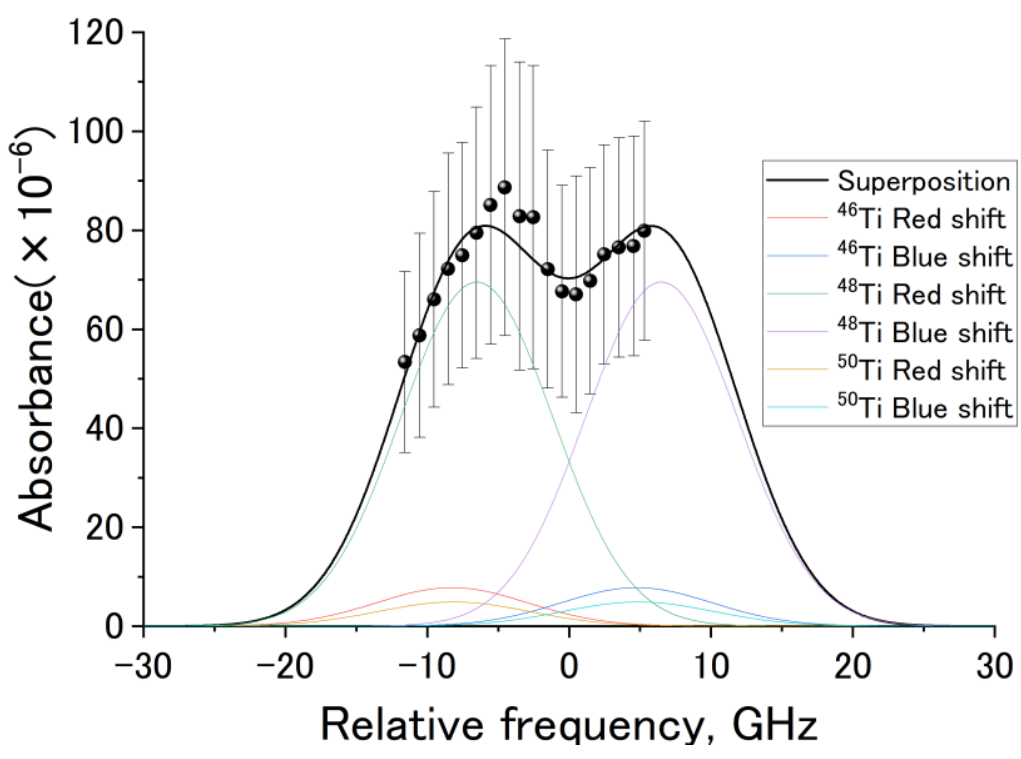

FIG. 5. Time-averaged spectrum calculated using the ring-down time. 
TABLE I. Transition parameters for the ground state of Ti. ${ }^{15}$ Data available on request from the authors. 15. "P. Forsberg, NIST Atomic Spectra Database (ver. 5.7.1); licensed under a Creative Commons Attribution (CC BY) license."

\begin{tabular}{|c|c|c|c|c|c|c|}
\hline Transition & $\boldsymbol{\lambda}[\mathrm{nm}]$ & $\boldsymbol{A}_{\boldsymbol{k} \boldsymbol{i}}$ & $\boldsymbol{g}_{\boldsymbol{i}}$ & $\boldsymbol{g}_{\boldsymbol{k}}$ & $\boldsymbol{E}_{\boldsymbol{i}}[\mathrm{eV}]$ & $\boldsymbol{E}_{\boldsymbol{k}}[\mathrm{eV}]$ \\
\hline $\mathbf{4} \boldsymbol{s}^{\mathbf{2}} \boldsymbol{F}_{\mathbf{2}} \rightarrow \mathbf{4} \boldsymbol{p}^{\mathbf{3}} \boldsymbol{D}_{\mathbf{1}}$ & 394.867 (air) & $5.60 \times 10^{7}$ & 5 & 3 & 0 & 3.139 \\
\hline
\end{tabular}

TABLE II. List of abundance ratios. ${ }^{24}$ Data available on request from the authors. "J. R. De Laeter et., Pure Appl. Chem. 75, 683 (2003); licensed under a Creative Commons Attribution (CC BY) license."

\begin{tabular}{|c|c|}
\hline Isotope & Abundance ratio \\
\hline${ }^{46} \mathbf{T i}$ & 0.0825 \\
\hline${ }^{\mathbf{4 8}} \mathbf{T i}$ & 0.7372 \\
\hline${ }^{{ }^{50}} \mathbf{T i}$ & 0.0518 \\
\hline
\end{tabular}

Two different peaks at relative frequencies of approximately -4.5 and $4.5 \mathrm{GHz}$, corresponding to 394.86474 and $394.86942 \mathrm{~nm}$, respectively, are observed due to the under-cosine shape ${ }^{25}$ of the spatial distribution of the differential sputtering yield. ${ }^{26}$ The density of sputtered titanium atoms in the ground state is relatively low around the central axis. As a result, two peaks appear at the relative frequencies of -4.5 and $4.5 \mathrm{GHz}$. The measurement uncertainty for the time-averaged measurements was calculated to be 29.9 parts-per-million (ppm; $1 \mathrm{ppm}$ corresponds to $10^{-6}$ ), which was evaluated using the standard deviation as shown in Fig. 5. Thus, the path-integrated number density and uncertainty were $1 \times 10^{13}$ and $2 \times 10^{12} \mathrm{~m}^{-2}$, respectively. The uncertainty was $20 \%$, which is relatively large because the absorbance histogram of the bins from -4 to $-5 \mathrm{GHz}$ reveals a bimodal distribution instead of unimodal, as shown in Fig. 6. As this was not a Gaussian distribution, the uncertainty was assessed using the standard deviation instead of the standard error. This histogram was obtained from a total of 241 ring-down signals and shows how often each absorbance was obtained in a given bin. The vertical line represents the occurrence probability, which was calculated by dividing the number of absorbances in each bin by the total absorbance. This shows whether the distribution of the absorbance was unimodal or not. If the absorbance is governed only by statistical fluctuations, the histogram should have a unimodal distribution. The histogram in Fig. 6 is not unimodal, indicating the absorbance under these conditions fluctuates due to statistical fluctuations and other reasons, such as discharge current oscillations in the Hall thruster. As the data are not homoscedastic, it is considered that the acquired ring-down times are derived from different populations rather than a single population. Therefore, the uncertainty cannot be evaluated based on the standard error, but instead requires evaluation based on the data variability. This motivates the time-resolved analysis of erosion estimation in Hall thrusters. 


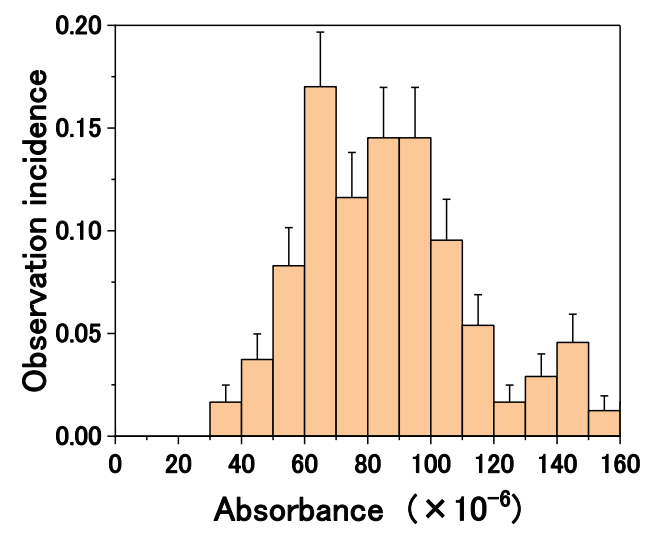

FIG. 6. Histogram of the time-averaged absorbance for $10 \mathrm{ppm}$ bins from -4 to $-5 \mathrm{GHz}$.

\section{B. Time-resolved CRDS}

The time-resolved CRDS absorbance signals are given in Fig. 7. The absorbance was large when the normalized time was from 0.4 to 0.5 with a relative frequency from -4 to $-5 \mathrm{GHz}$ or 4 to 5 GHz. In contrast, the absorbance was small when the normalized time was 0.0 to 0.2 and 0.8 to 1.0 . Normalized times between 0.4 to 0.5 ( 0.0 to 0.1 and 0.9 to 1.0 ) correspond to the time of the maximum (minimum) discharge current. The dependence of the absorbance on the normalized time originates from the discharge current oscillations.

Histograms of the time-resolved absorbance for the -4 to $-5 \mathrm{GHz}$ bin with normalized times of 0.4 to 0.5 and 0.1 to 0.2 with a total of 31 and 22 ring-down times are presented in Figs. 8 and 9, respectively (the individual points in Fig. 7 were calculated using the data set in Fig. 8 or Fig. 9). The central axis of the distribution was $97.9 \mathrm{ppm}$ for the 0.4 to $0.5 \mathrm{bin}$ and $86.6 \mathrm{ppm}$ for the 0.1 to 0.2 bin. These data suggest that the amount of sputtered titanium atoms varied over time. In addition, Fig. 8 can be considered as unimodal, indicating a homoscedastic distribution. Therefore, for the time-resolved CRDS measurements, the uncertainty can be evaluated using the standard error and was evaluated as $6.36 \mathrm{ppm}$. In contrast, the histogram for the -4 to $-5 \mathrm{GHz}$ bins for the normalized times of 0.1 to 0.2 did not have a unimodal distribution; therefore, the uncertainty was evaluated from the data variability, which is large compared with the 0.4 to $0.5 \mathrm{GHz}$ bins. This is because the amplitude of the discharge current was not always the same every cycle, giving a fluctuating ion beam current into the target. Consequently, the amount of sputtered titanium atoms was non-uniform, even with the same normalized time.

The absorbance spectrum for normalized times between 0.4 to 0.5 is presented in Fig. 10. These data presented are related to the horizontal line in Fig. 7 for a normalized time from 0.4 to 0.5 . In this 
case, the fitting results indicate that the FWHM of the assumed Gaussian function was $6.3 \mathrm{GHz}$, and the frequency shift was $6.7 \mathrm{GHz}$. In addition, a 10\% fitting error was assumed for the Gaussian function.

Finally, the path-integrated number density was estimated for each normalized time. Time variations for the path-integrated number density of titanium atoms with the discharge current and voltage are shown in Fig. 11. The path-integrated number density oscillated from $8.3 \times 10^{12}$ to $1.08 \times 10^{13} \mathrm{~m}^{-2}$ with the discharge current, which yields an uncertainty of $6 \times 10^{11} \mathrm{~m}^{-2}$. Compared with the conventional time-averaged CRDS, which has a path-integrated number density of $1 \times 10^{13} \mathrm{~m}^{-2}$ and uncertainty of $2 \times 10^{12} \mathrm{~m}^{-2}$, the time-resolved CRDS reduces the uncertainty by $30 \%$. In addition, the path-integrated number density appears to lag slightly behind the discharge current. This phenomenon is ascribed to the fact that xenon ions take approximately $1 \mu$ s to reach the target, whereas the produced titanium atoms require approximately $2 \mu$ s to cross the laser path. Therefore, the peak path-integrated number density shifted by a normalized time of 0.06 relative to the discharge current.

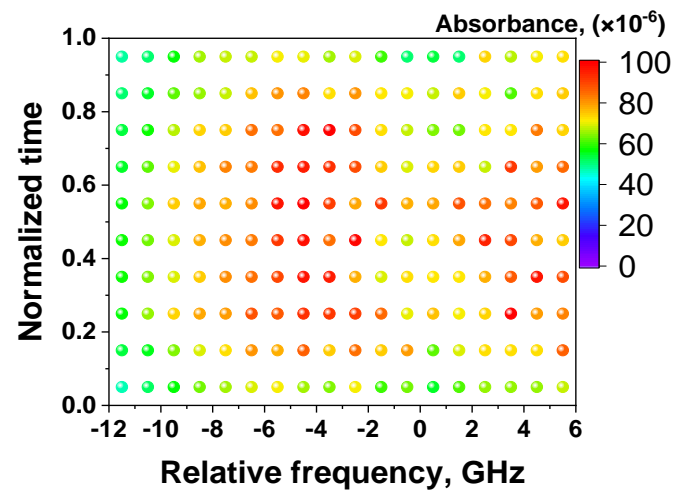

FIG. 7. Time-resolved CRDS absorbance spectra.

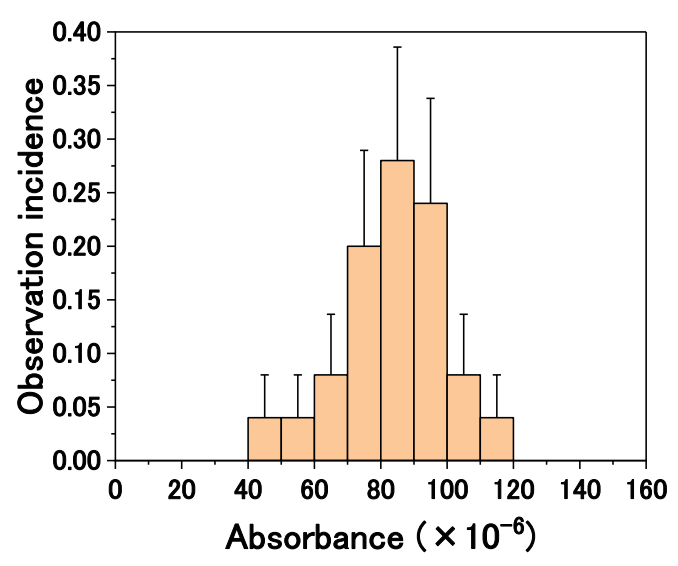

FIG. 8. Histogram of the time-resolved absorbance in the -4 to $-5 \mathrm{GHz}$ bin for a normalized time of 0.4 to 0.5 . 

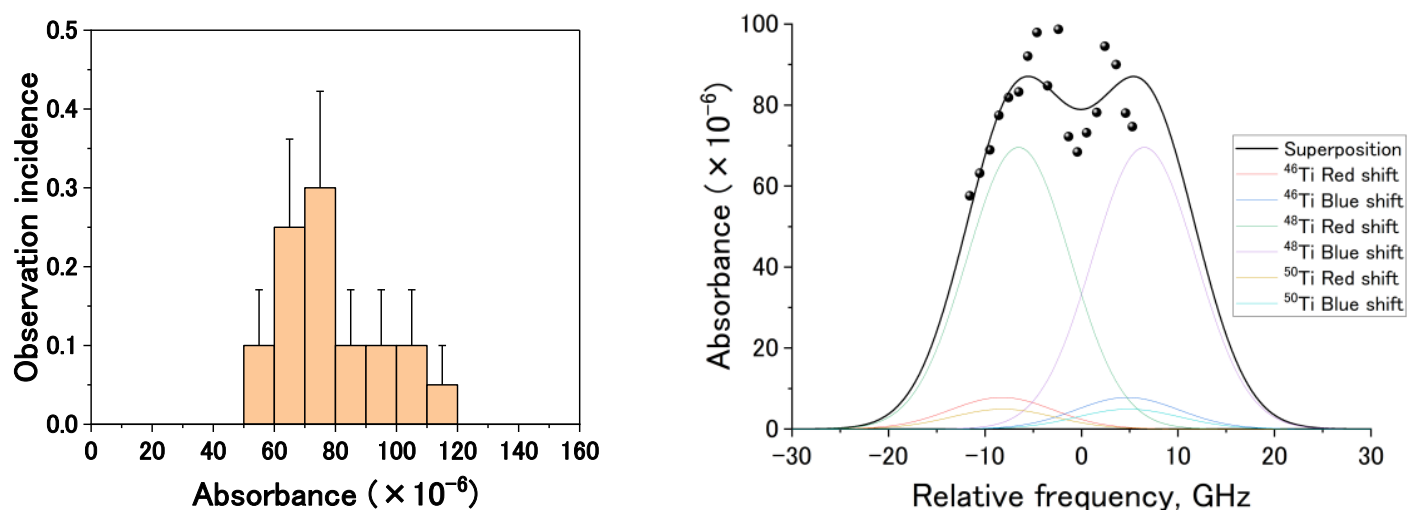

FIG. 9. Histogram of the time-resolved FIG. 10. Absorbance spectrum for a normalized absorbance in the -4 to $-5 \mathrm{GHz}$ bin for a time of 0.4 to 0.5 . normalized time of 0.1 to 0.2 .

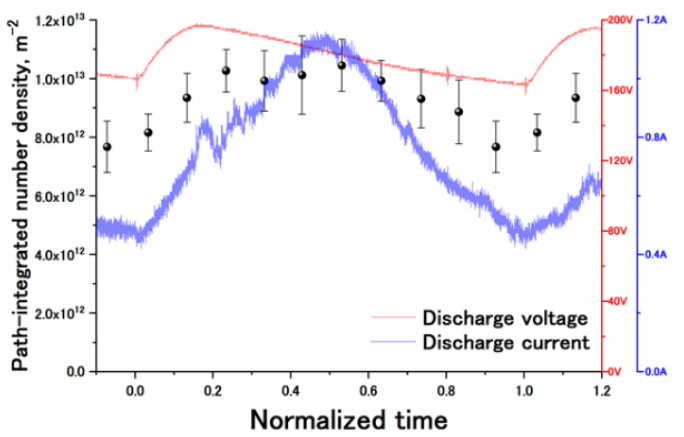

FIG. 11. Time variation for the path-integrated number density of titanium atoms.

\section{CONCLUSION}

A titanium erosion sensor based on time-resolved CRDS was developed to assess wall erosion in Hall thrusters. The time-resolved CRDS results confirm that the path-integrated number density of sputtered titanium particles oscillated from $8.3 \times 10^{12}$ to $1.08 \times 10^{13} \mathrm{~m}^{-2}$ with the discharge current. Additionally, the studies permitted measuring the uncertainty by assessing the standard error, which improved the uncertainty from $2 \times 10^{12}$ to $6 \times 10^{11} \mathrm{~m}^{-2}$ compared to the time-averaged CRDS. The proposed system proved effective at sensing titanium erosion and is suitable to optimize the lifetime of Hall thrusters.

In this study, the spectrum was fit using a Gaussian distribution for simplicity. A finite-element method for the sputtering ${ }^{27}$ using the Thompson distribution ${ }^{28}$ will be examined in future work. In addition, the intention is to measure the sputtered atom density from the wall using the time-resolved 
CRDS system to optimize the magnetic field configuration in the Hall thruster.

\section{ACKNOWLEDGMENTS}

This work was supported by the Japan Society for the Promotion of Science (JSPS) KAKENHI (Grant No. JP18H03815), Mitsubishi Electric Corporation, and the Japan Aerospace Exploration Agency (JAXA).

\section{DATA AVAILABILITY}

The data that support the findings of this study are available from the corresponding author upon reasonable request.

\section{REFERENCES}

${ }^{1}$ C. Casaregola, "Electric propulsion for station keeping and electric orbit raising on Eutelsat platforms," IEPC-2015-96/ISTS-2015-b-96, Joint Conference of 30th International Symposium on Space Technology and Science, 34th International Electric Propulsion Conference and 6th Nano-satellite Symposium, Hyogo-Kobe, Japan, July 2015.

2 J. J. Likar, A. Bogorad, K. A. August, R. E. Lombardi, K. Kannenberg, and R. Herschitz, IEEE Trans. Plasma Sci. 43, 3009 (2015).

3 Space News, "Contact lost with three Starlink satellites, other 57 healthy," July 1, 2019, https://spacenews.com/contact-lost-with-three-starlink-satellites-other-57-healthy/.

4 Room, "Europe's first all-electric telecom satellite breaks record," October 18, 2017, https://room.eu.com/news/europes-first-all-electric-telecom-satellite-breaks-record.

${ }^{5}$ K. Kuriki and Y. Arakawa, Introduction to Electric Propulsion (University of Tokyo Press, Tokyo, 2003) (in Japanese).

${ }^{6}$ C. E. Gamer, J. E. Polk, L. C. Pless, K. D. Goodfellow, and J. R. Brophy, "Performance evaluation and life testing of the SPT-100," 23rd International Electric Propulsion Conference, IEPC-93-091, Seattle, Washington, September 13-16, 1993.

${ }^{7}$ P. Y. Peterson and D. H. M. Manzella, "Investigation of the erosion characteristics of a laboratory Hall thruster," AIAA Paper 2003-5005 (2003).

${ }^{8}$ B. C. Lee, A. P. Yalin, A. Gallimore, W. Huang, and H. Kamhawi, "Real-time boron nitride erosion measurements of the HiVHAc thruster via cavity ring-down spectroscopy," 33rd International Electric Propulsion Conference, IEPC-2013-119, Washington, D. C., October 7-10, 2013.

${ }^{9}$ B. C. Lee, W. Huang, L. Tao, N. Yamamoto, A. D. Gallimore, and A. P. Yailin, Rev. Sci. Instrum. 85, 053111 (2014).

${ }^{10}$ G. Berden, R. Peeters, and G. Meijer, Int. Rev. Phys. Chem. 19, 556 (2000).

${ }^{11}$ A. Yamaguchi, A. Kibe, N. Yamamoto, T. Morita, and H. Nakashima, Trans. JSASS Aerospace 
Technol. Jpn. 14, 111 (2016).

${ }^{12}$ N. Yamamoto, L. Tao, B. Rubin, J. D. Williams, and A. P. Yalin, J. Propul. Power 26, 142 (2010).

${ }^{13}$ L. Tao, N. Yamamoto, and A. P. Yalin, Rev. Sci. Instrum. 79, 115107 (2008).

14 A. Yamaguchi, "The investigation of erosion in Hall thruster by using cavity ring-down spectroscopy," Master's thesis, Kyushu University, 2015 (in Japanese).

15 P. Forsberg (1991). NIST Atomic Spectra Database (ver. 5.7.1), Available: https://physics.nist.gov/asd [2020, July 31]. National Institute of Standards and Technology, Gaithersburg, MD. DOI: https://doi.org/10.1088/0031-8949/44/5/008.

${ }^{16}$ K. Busch and M. Busch, "Cavity-Ringdown Spectroscopy," ACS Symposium Series 720, (Oxford University Press, 1999).

${ }^{17}$ W.-G. Jin, Y. Nemoto, and T. Minowa, J. Phys. Soc. Jpn. 78, 094301 (2009).

${ }^{18}$ N. Yamamoto, H. Takegahara, J. Aoyagi, K. Kuriki, T. Tamida, and H. Osuga, IEEE Trans. Plasma Sci. 43, 158 (2015).

${ }^{19}$ T. Tamida, H. Osuga, N. Yamamoto, H. Takegahara, J. Aoyagi, and K. Kuriki, J. Propul. Power 31, 956 (2015).

${ }^{20}$ M. Matsui, "Application of Laser Absorption Spectroscopy to High Enthalpy Flow Diagnostics," PhD Dissertation, The University of Tokyo, 2005.

${ }^{21}$ W. Demtroder, "Laser Spectroscopy," second ed., (Berlin, Springer Verlag, 1996).

${ }^{22}$ A. P. Yalin and V. Surla, "Determination of number density of sputtered particles by cavity ring-down spectroscopy," Proceedings of the 29th International Electric Propulsion Conference, IEPC paper 2005-300 (2005).

${ }^{23}$ M. Matsui, S. Yokota, K. Komurasaki, and Y. Arakawa, "Evaluation of Unionized Propellant Xenon Atom in a Hall Thruster Plume," AIP Conference Proceedings, Rarefied gas dynamics: Proceedings of the 26th International Symposium on Rarefied Gas Dynamics, RGD26, Kyoto, Japan, 20-25 July 2008, 1084(1), 889-894.

${ }^{24}$ J. R. De Laeter, J. K. Böhlke, P. D. Bièvre, H. Hidaka, H. S. Peiser, K. J. R. Rosman, and P. D. P. Taylor, Pure Appl. Chem. 75, 683 (2003).

${ }^{25}$ A. H. Simon, "Sputtering Processing in Handbook of Thin Film Deposition (Third Edition)," ELSEVIER 55-88 (2012).

${ }^{26}$ J. L. Topper, "Total and Differential Sputter Yield of Boron Nitride," Master's Thesis, Colorado State University, 2011.

${ }^{27}$ A. P. Yalin, J. D Williams, V. Surla, J. Wolf, and K. A. Zoerb, "Azimuthal Differential Sputter Yields of Molybdenum by Low Energy Xe ${ }^{+}$Bombardment," 42nd AIAA/ASME/SAE/ASEE Joint Propulsion Conference \& Exhibit, Hartford, Connecticut, July 9-12, 2006.

${ }^{28}$ V. Surla and A. P. Yalin, Appl. Opt. 46, 3987 (2007). 


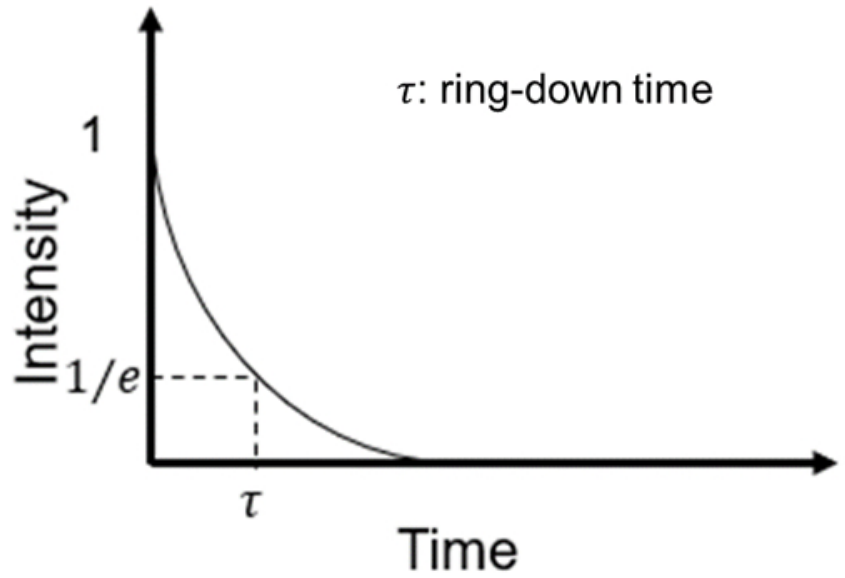




\section{Vacuum chamber}

\section{Mirror}

\section{Beam splitter}

( High-reflection

mirror

$\underset{\text { Laser }}{\text { Voltage signal }}$
$\underset{\text { Chopping signal }}{\text { Data................ transmission }}$

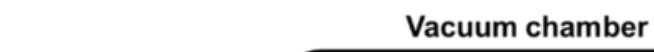




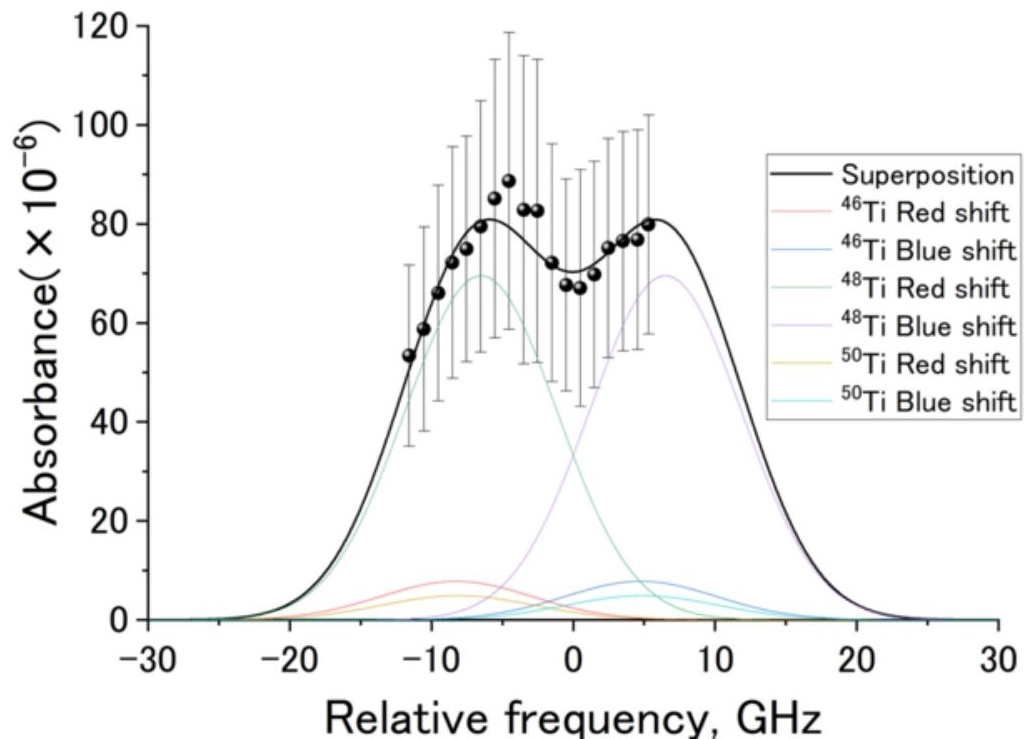




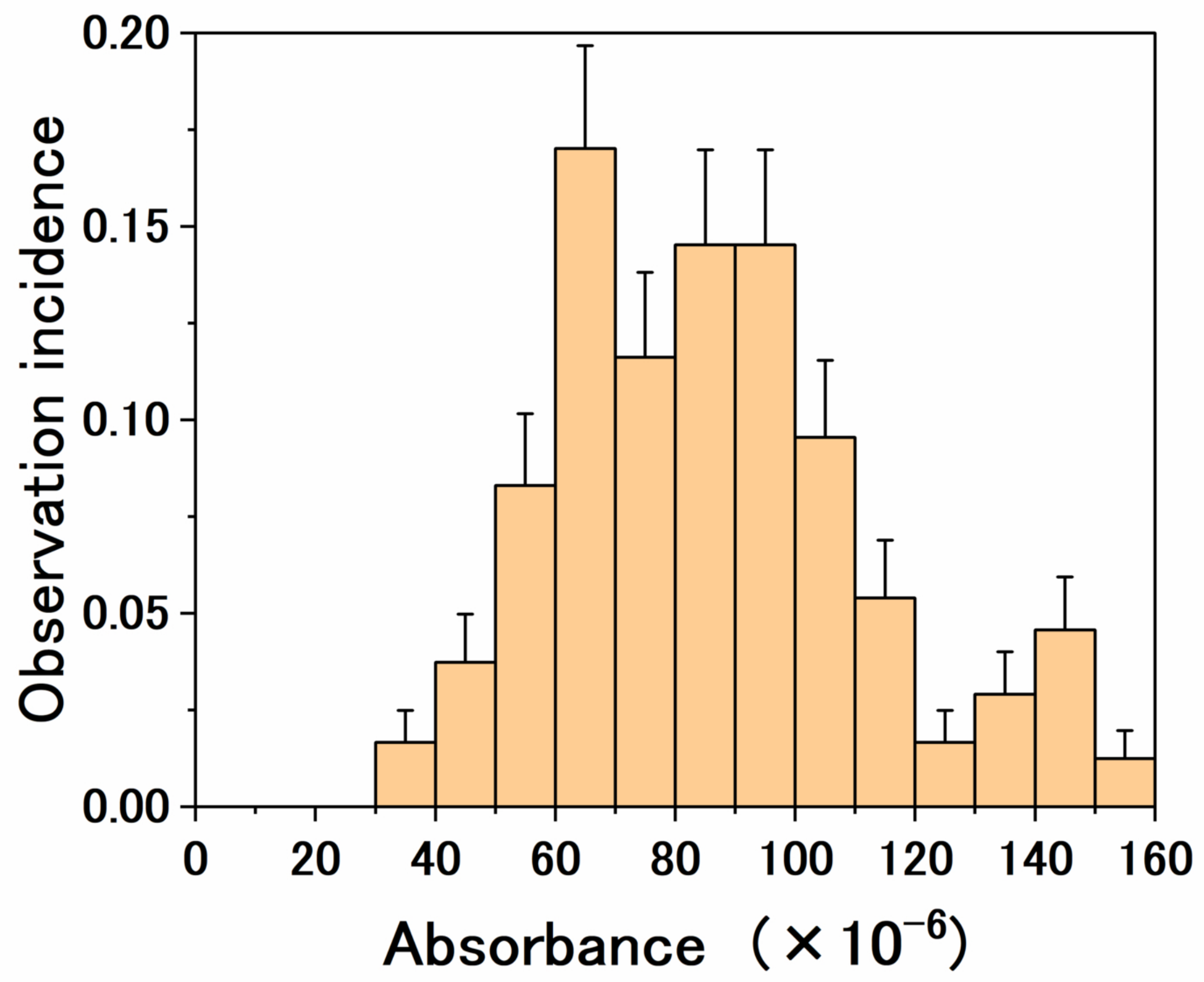




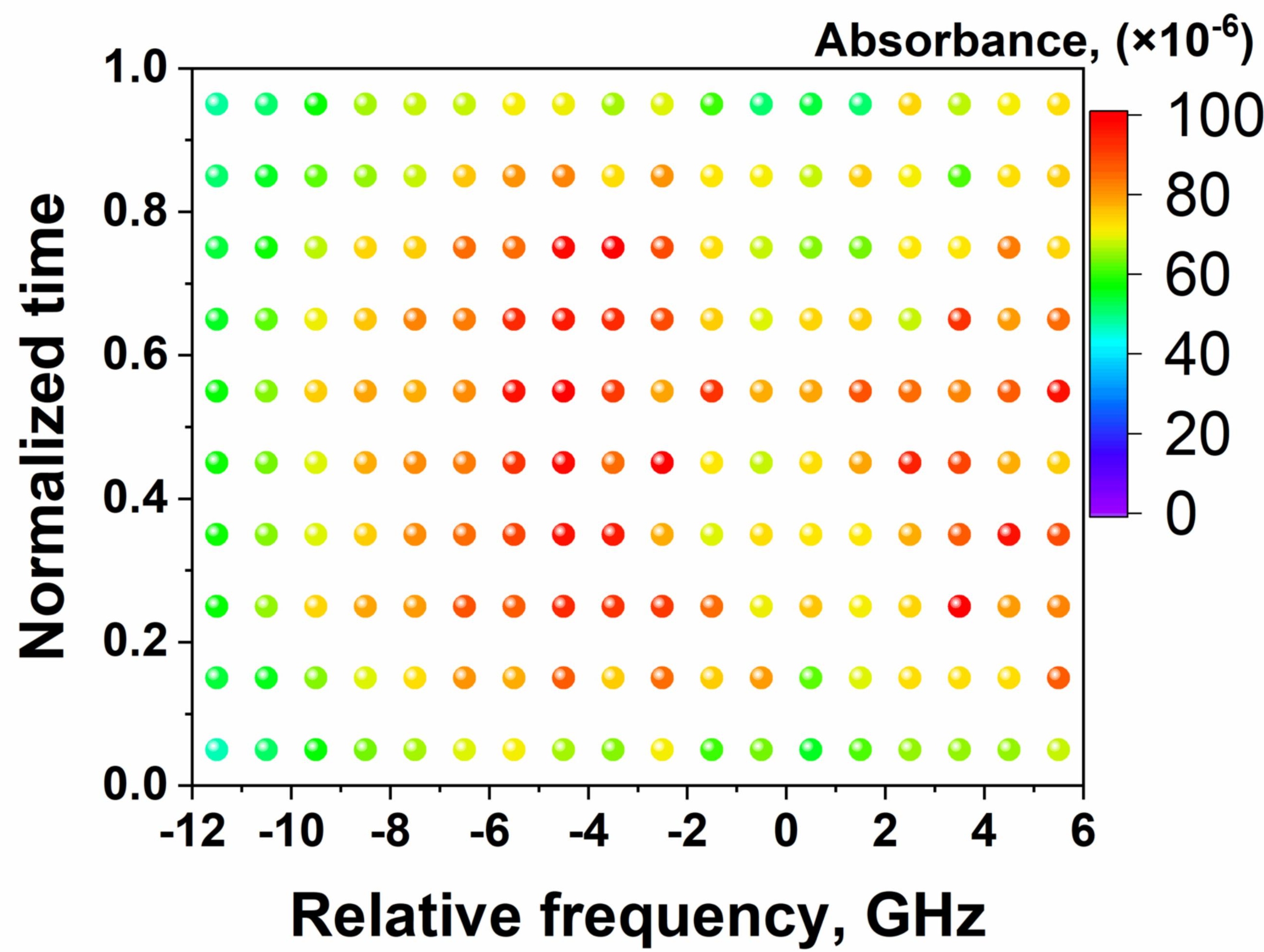




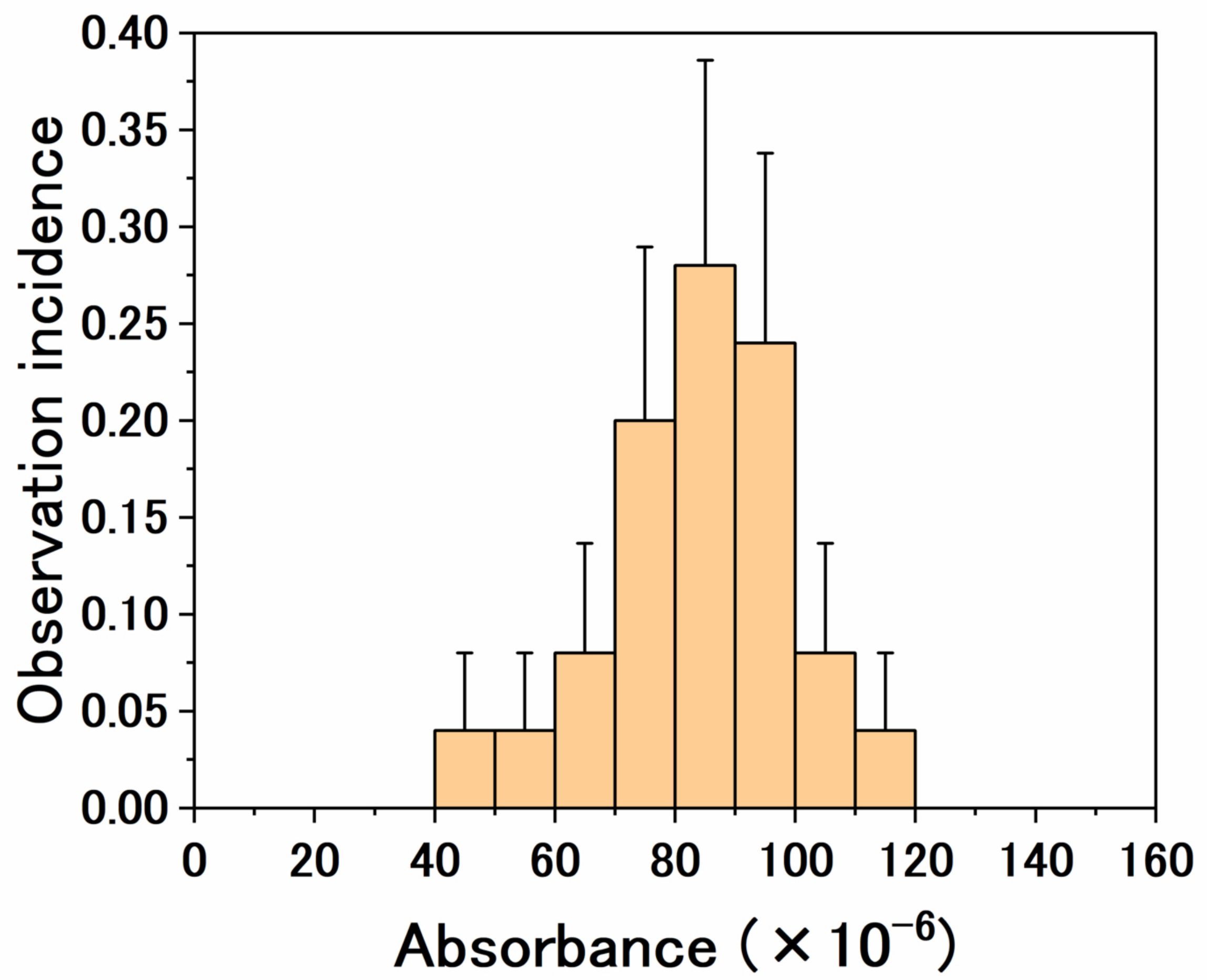




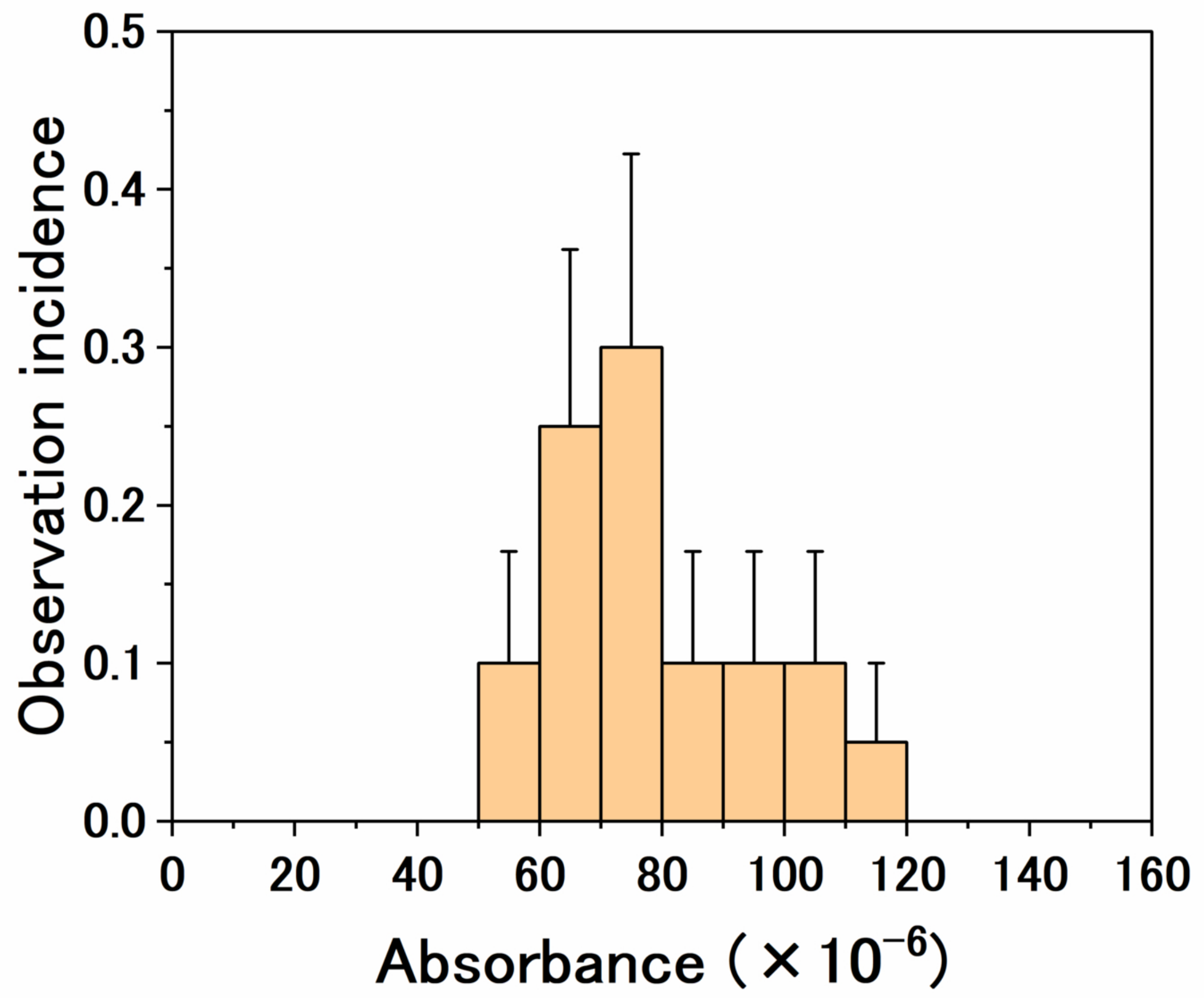




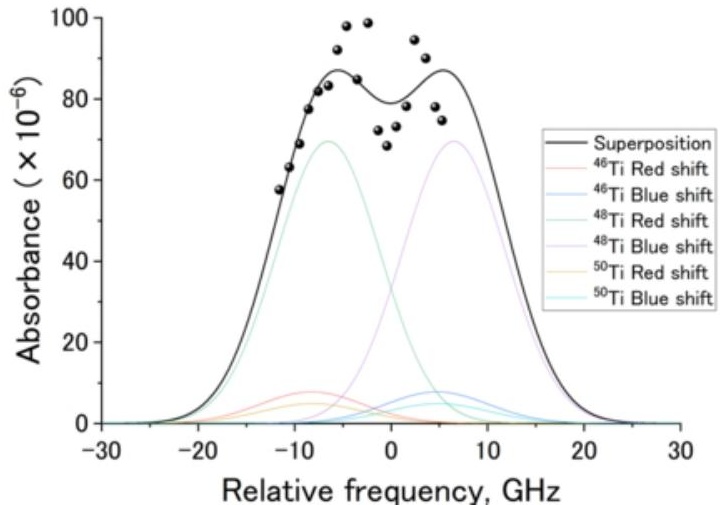




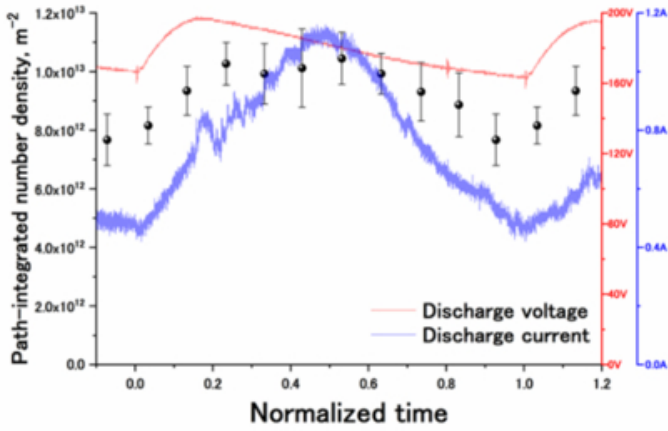

